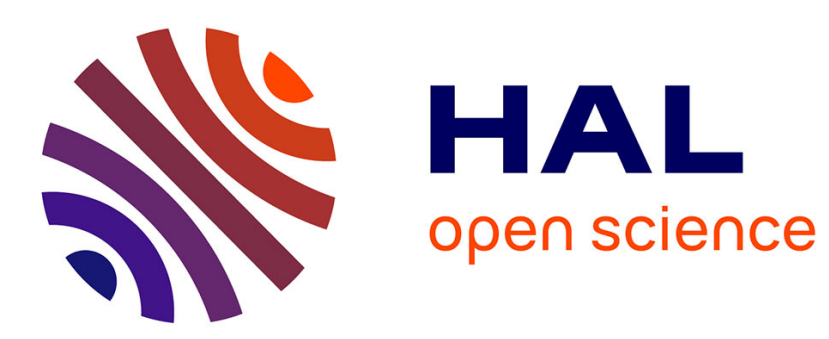

\title{
La violence d'Etat comme mode de régulation de la croissance urbaine: le cas de Khartoum (Soudan),
}

Marc Lavergne

\section{To cite this version:}

Marc Lavergne. La violence d'Etat comme mode de régulation de la croissance urbaine: le cas de Khartoum (Soudan),. Espace Populations Sociétés, 1997, 1997-1, p. 49-64. halshs-00530198

\section{HAL Id: halshs-00530198 \\ https://shs.hal.science/halshs-00530198}

Submitted on 27 Oct 2010

HAL is a multi-disciplinary open access archive for the deposit and dissemination of scientific research documents, whether they are published or not. The documents may come from teaching and research institutions in France or abroad, or from public or private research centers.
L'archive ouverte pluridisciplinaire HAL, est destinée au dépôt et à la diffusion de documents scientifiques de niveau recherche, publiés ou non, émanant des établissements d'enseignement et de recherche français ou étrangers, des laboratoires publics ou privés. 


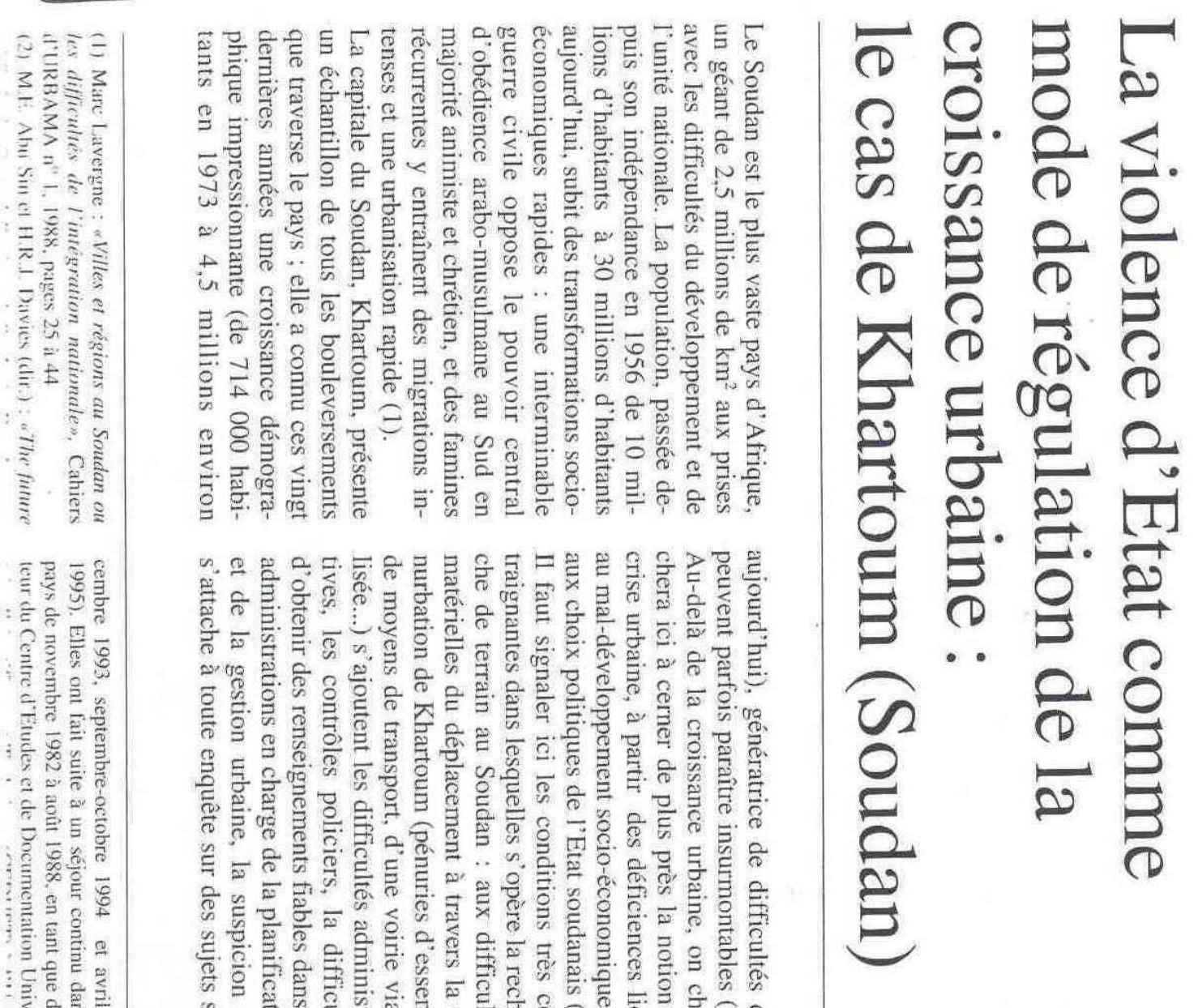
क 


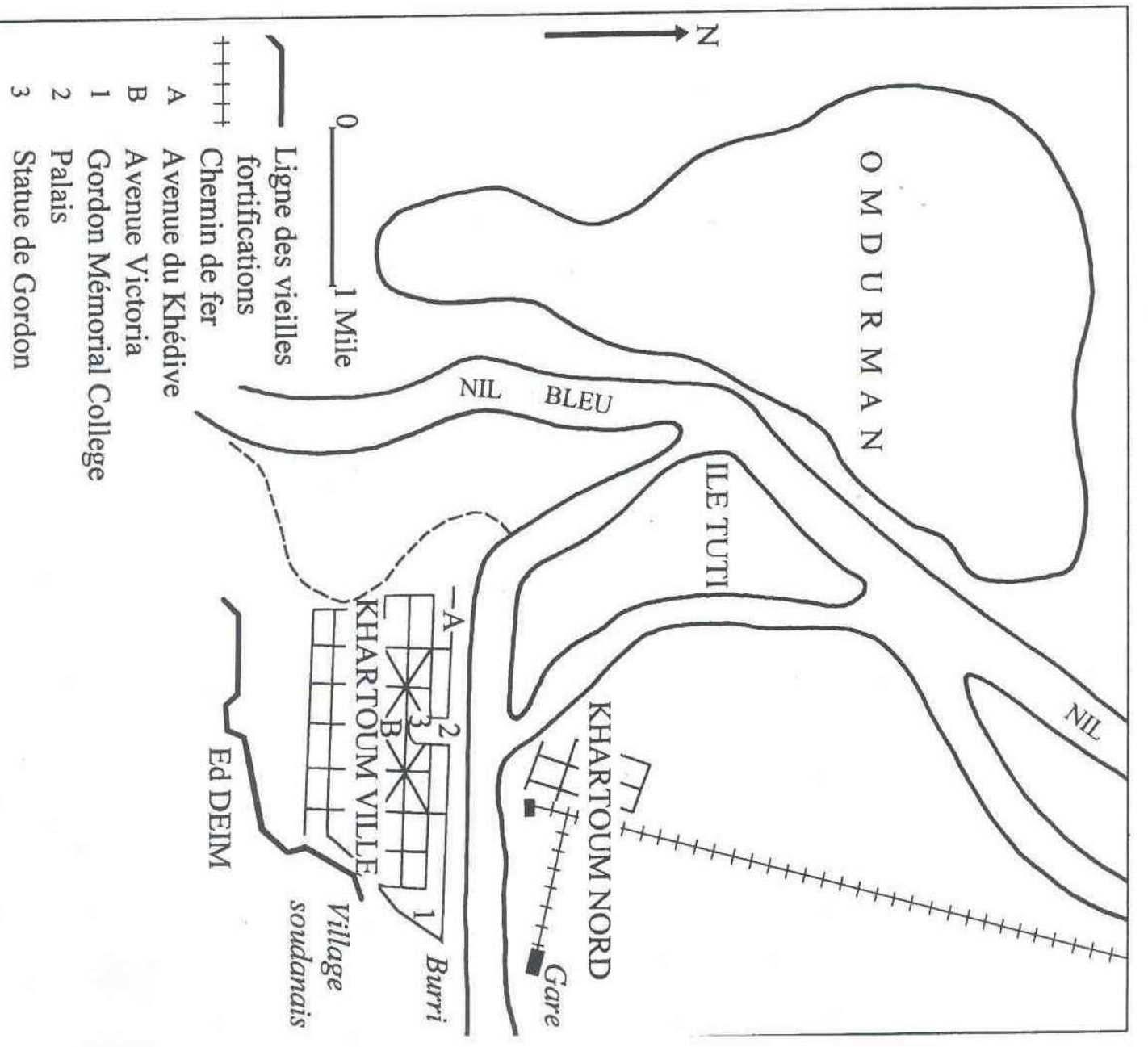




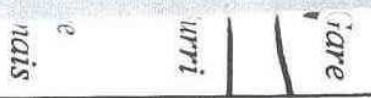

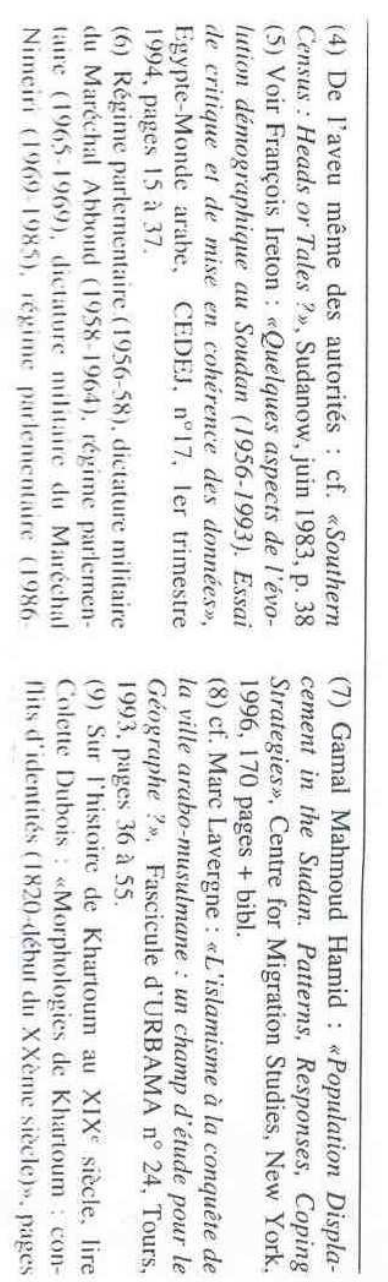

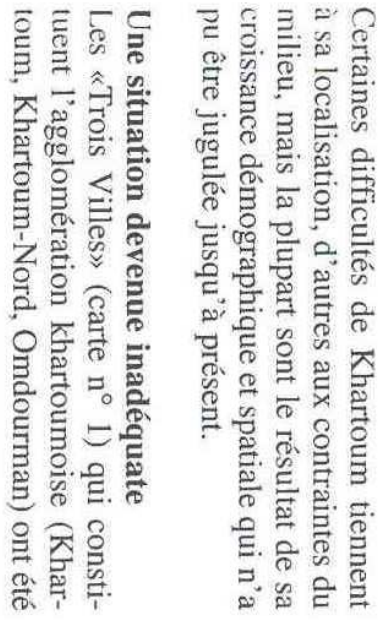

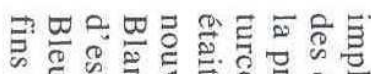

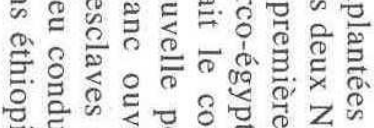

可.

$=0.0$

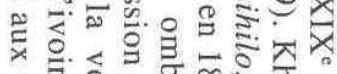

उ. 궁

हैं

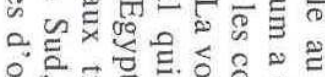

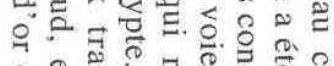

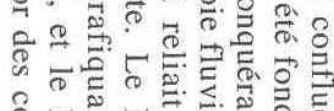

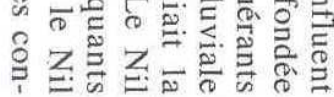

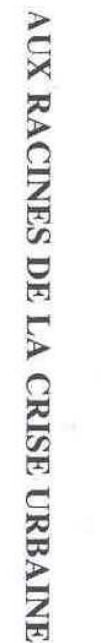

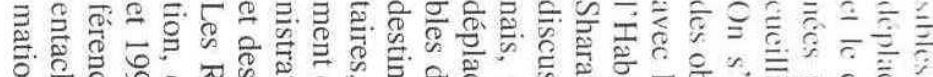

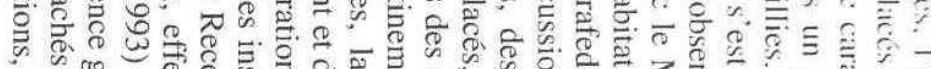

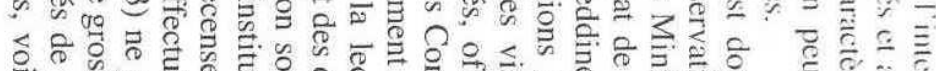

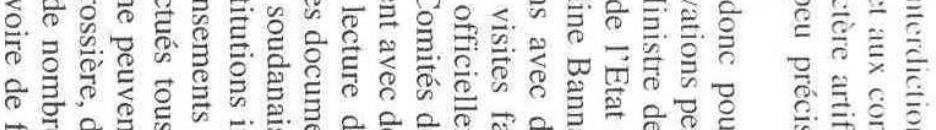

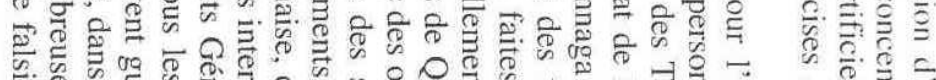
एक.

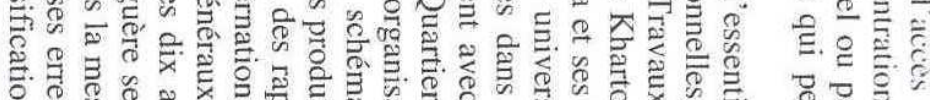

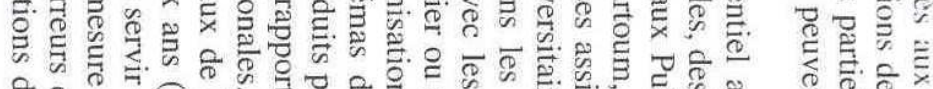

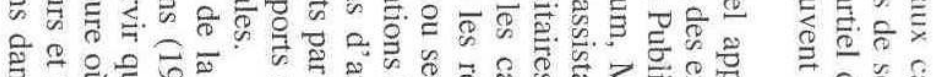

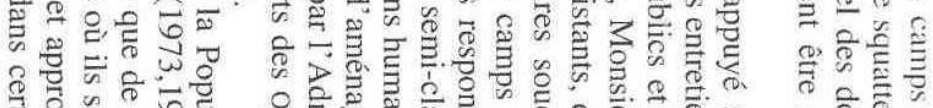

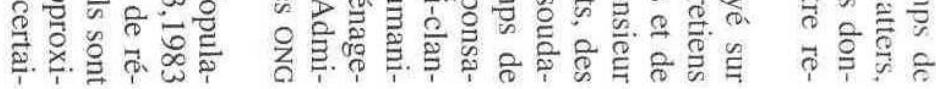

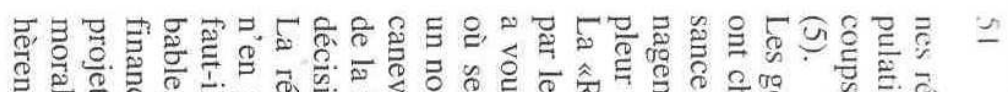

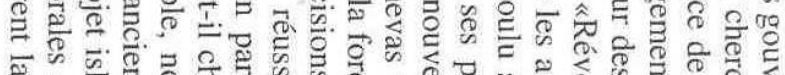

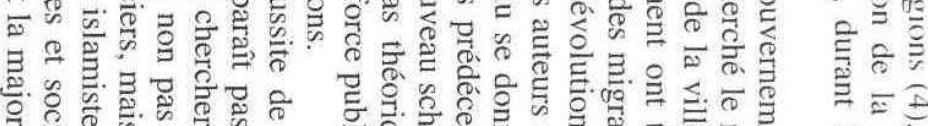

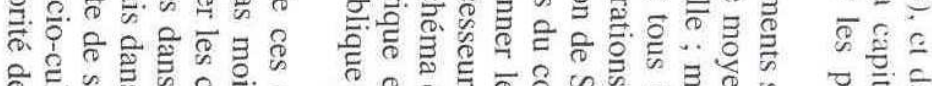
के

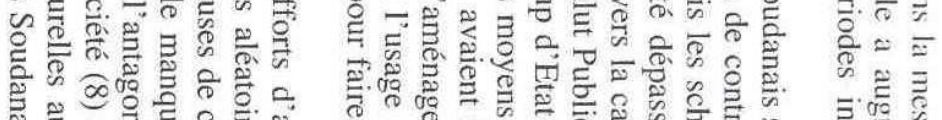

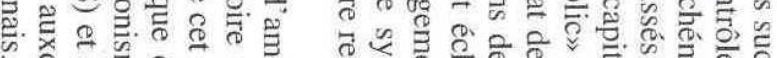

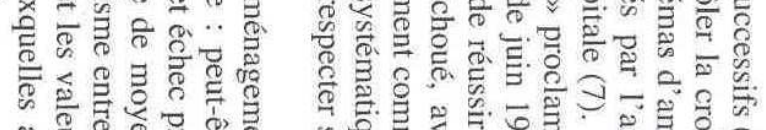

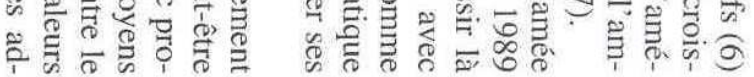

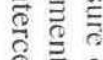
릉. 证 


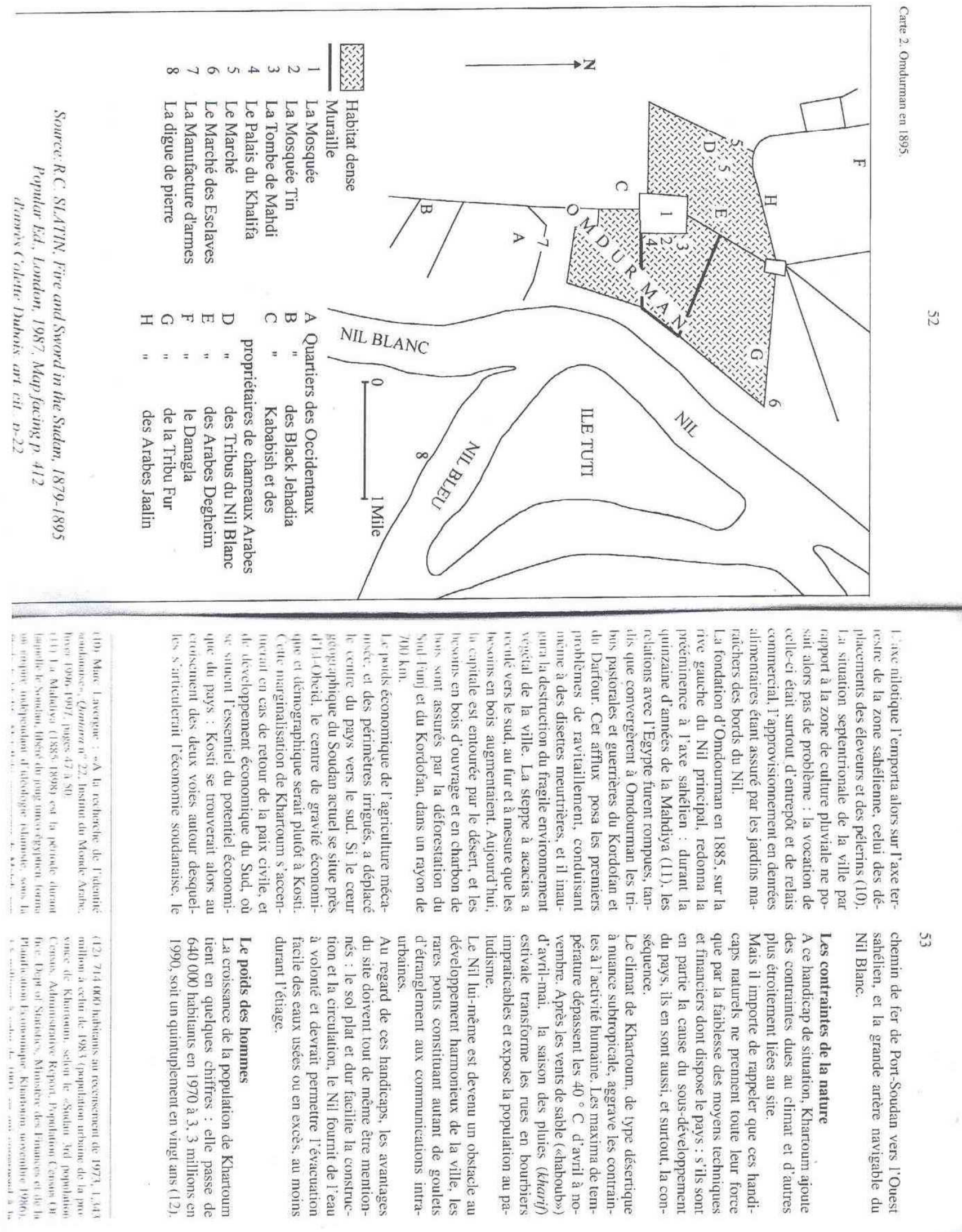




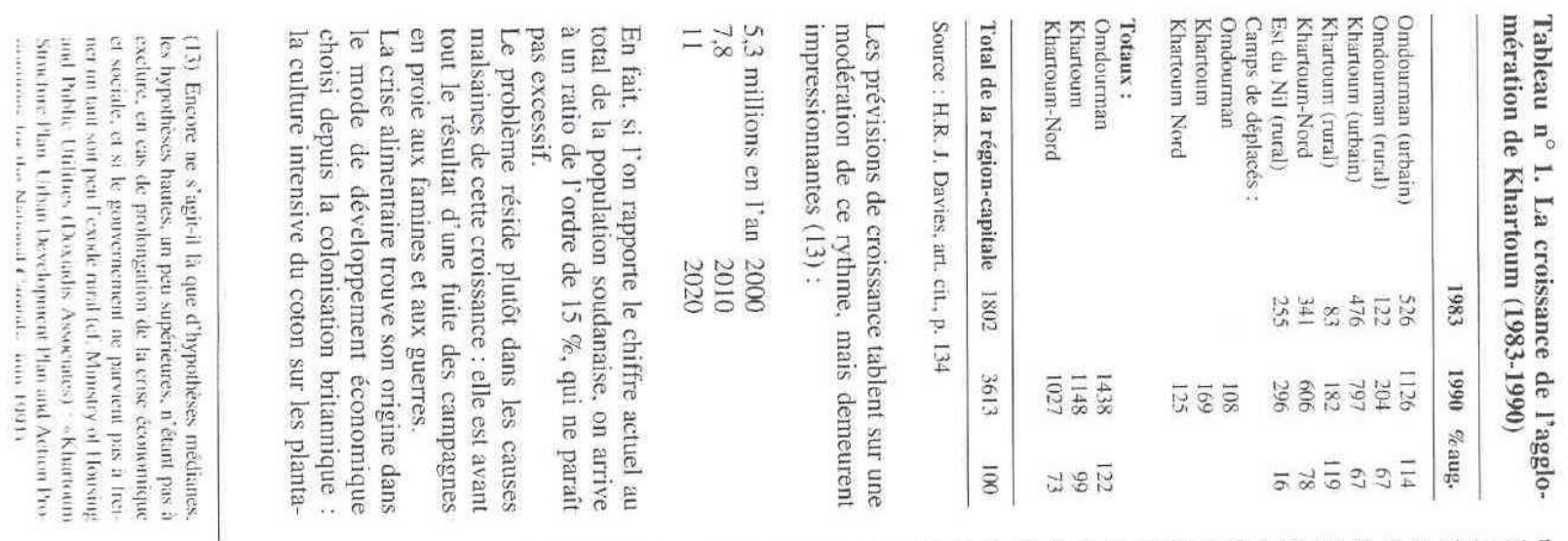

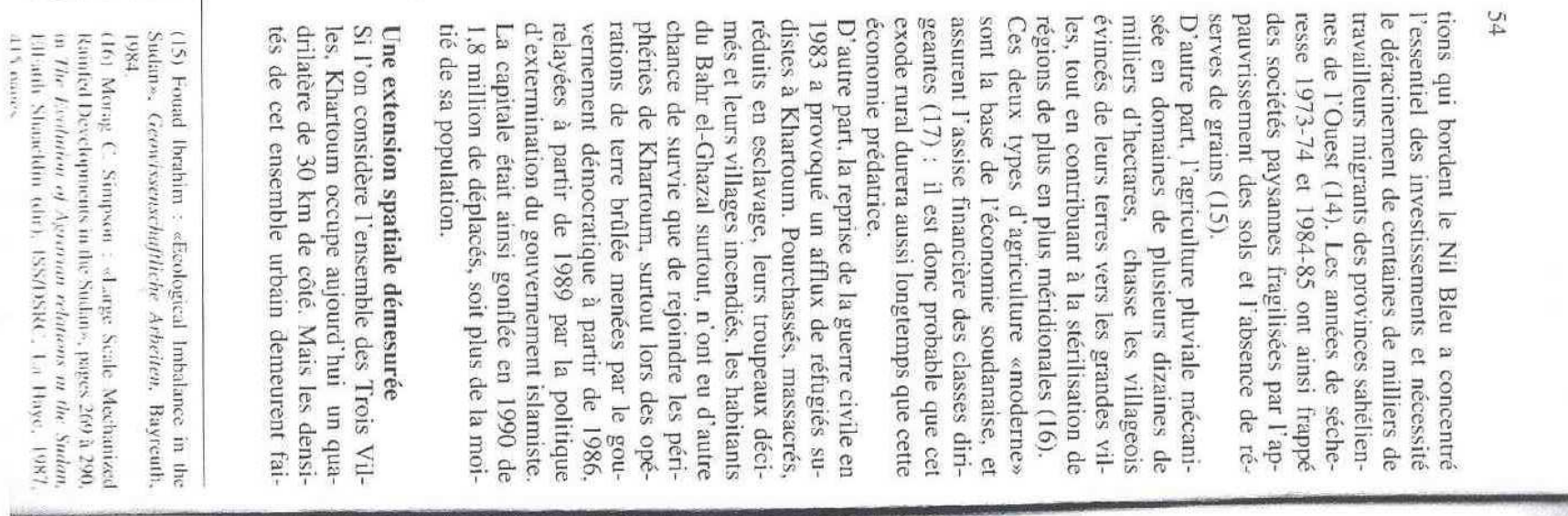

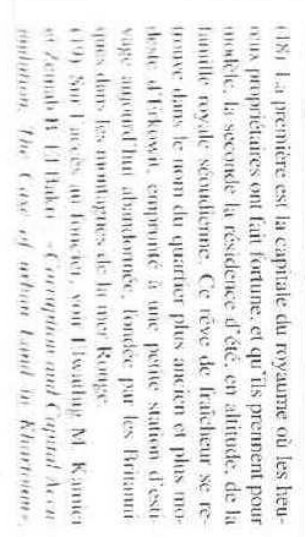

틀

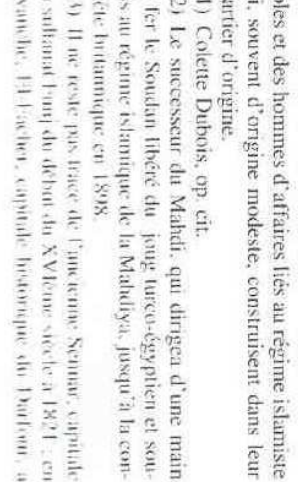

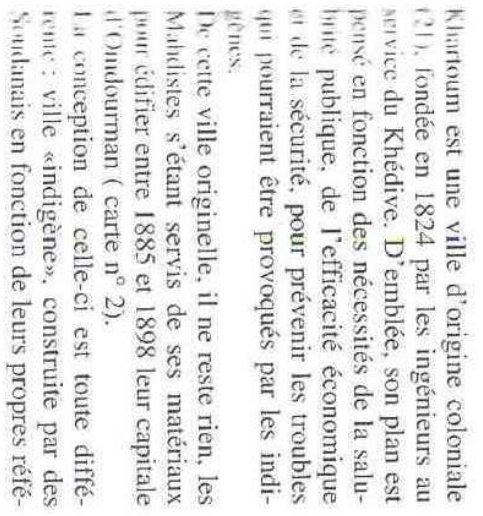

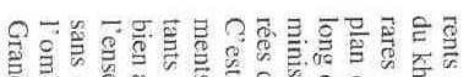

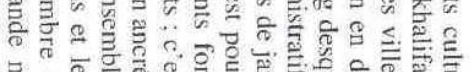

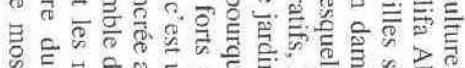

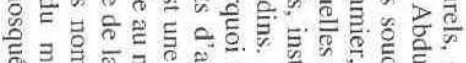

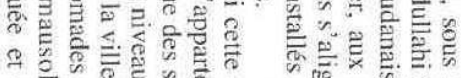

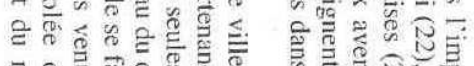

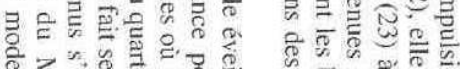

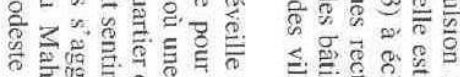

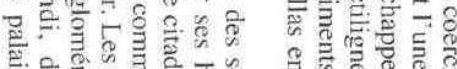

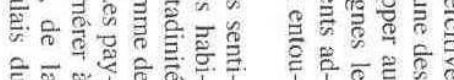

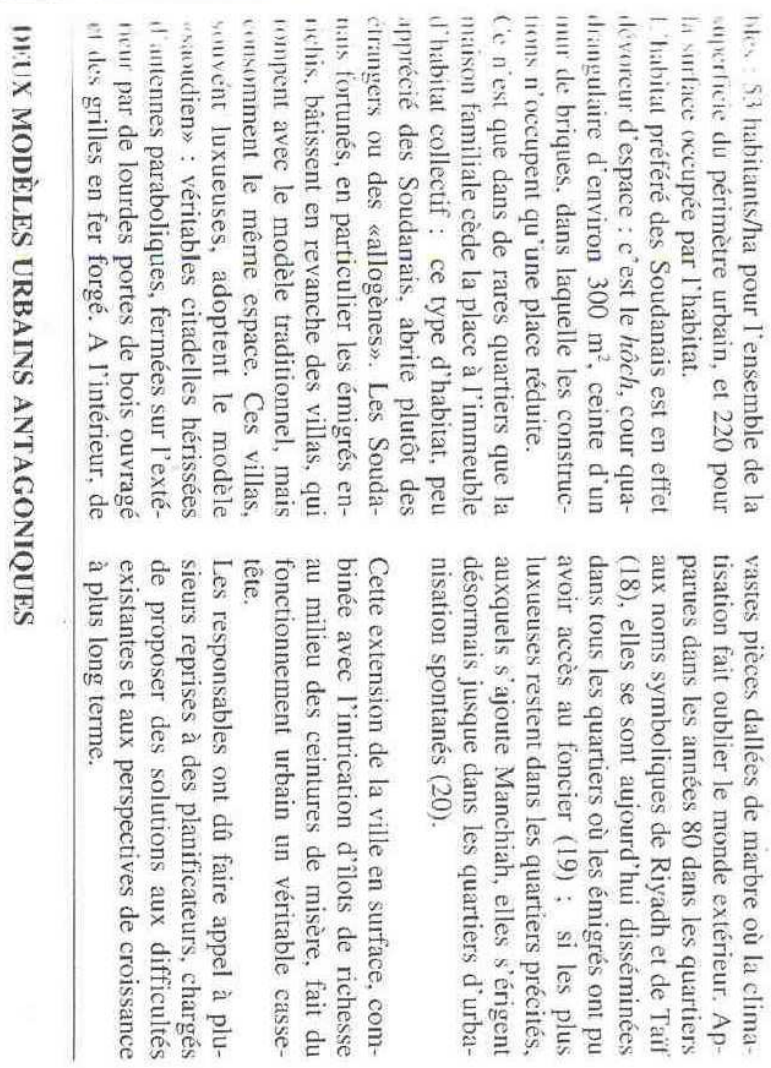



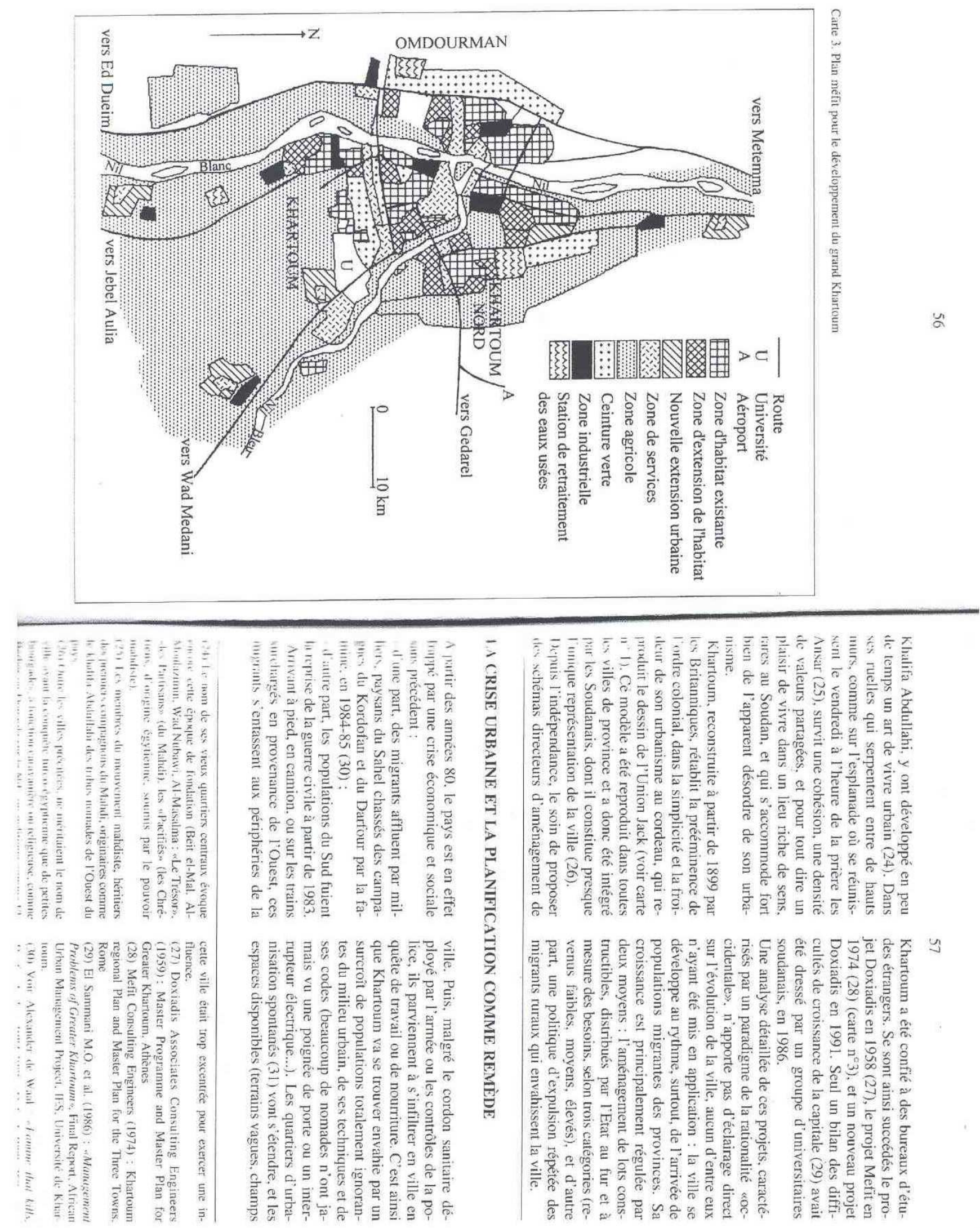

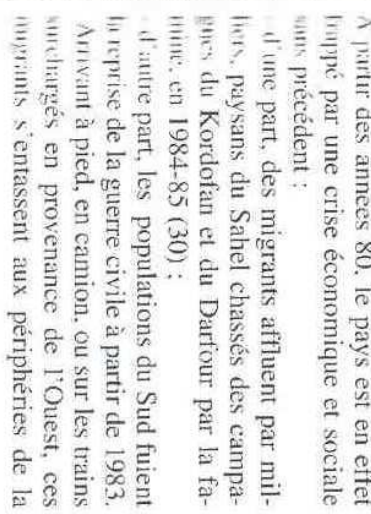

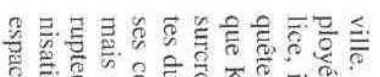
है

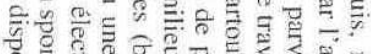

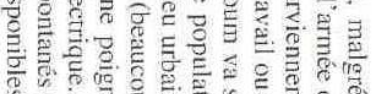
क

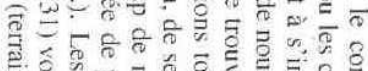

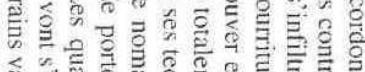
๙

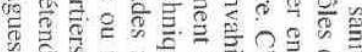

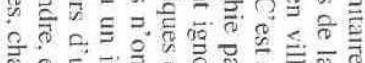

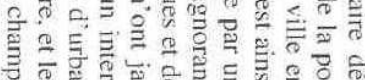

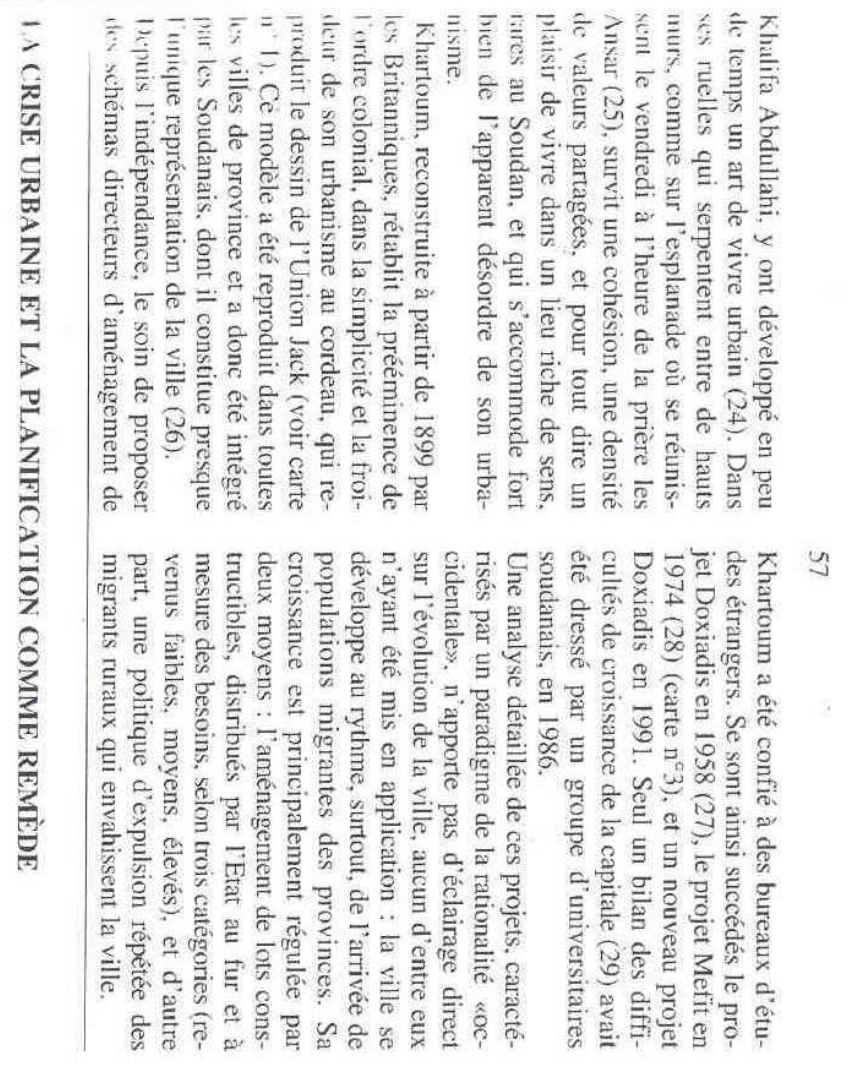




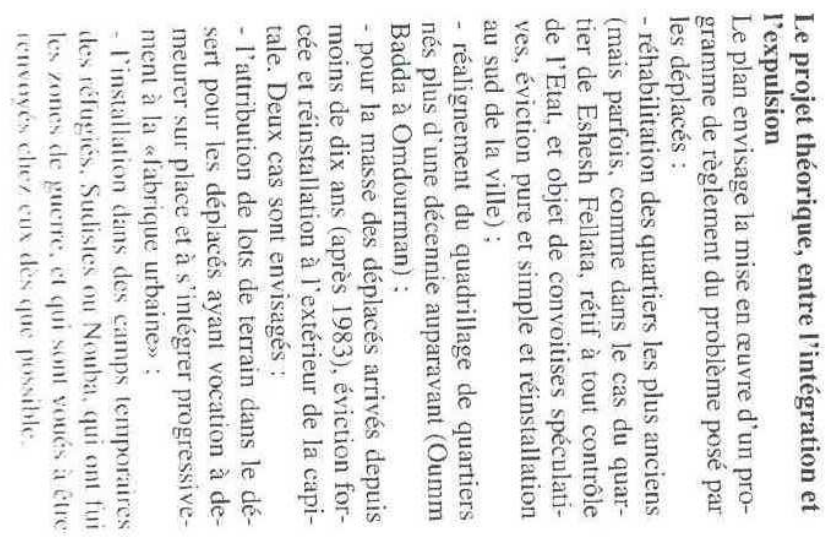

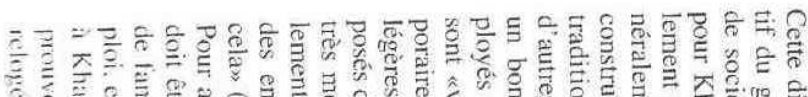

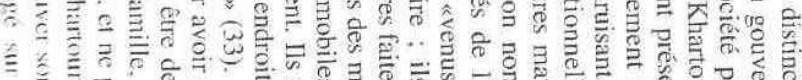

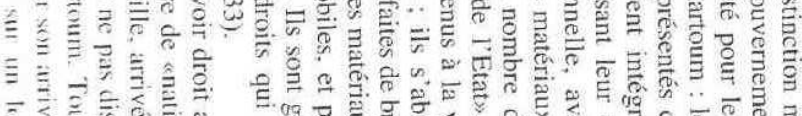

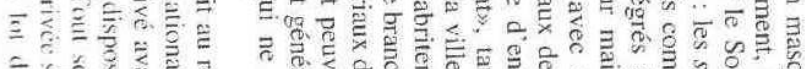

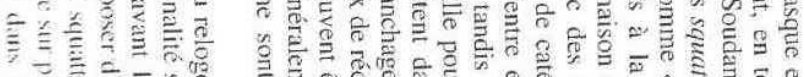

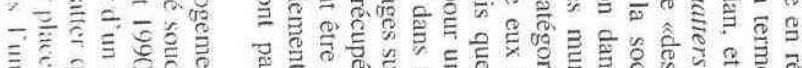

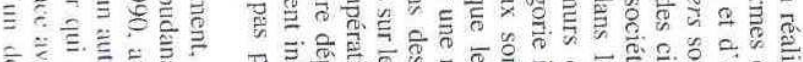

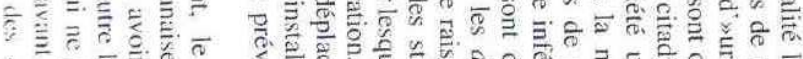

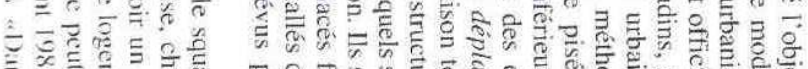

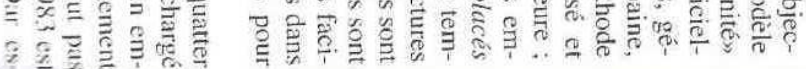

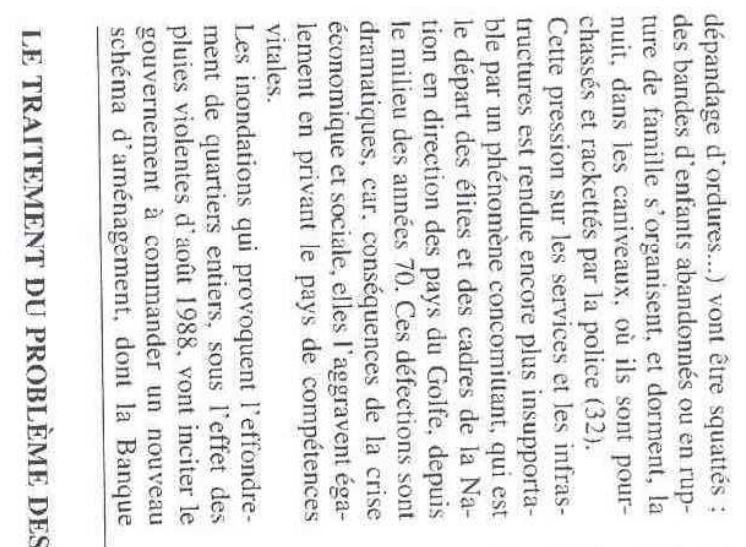

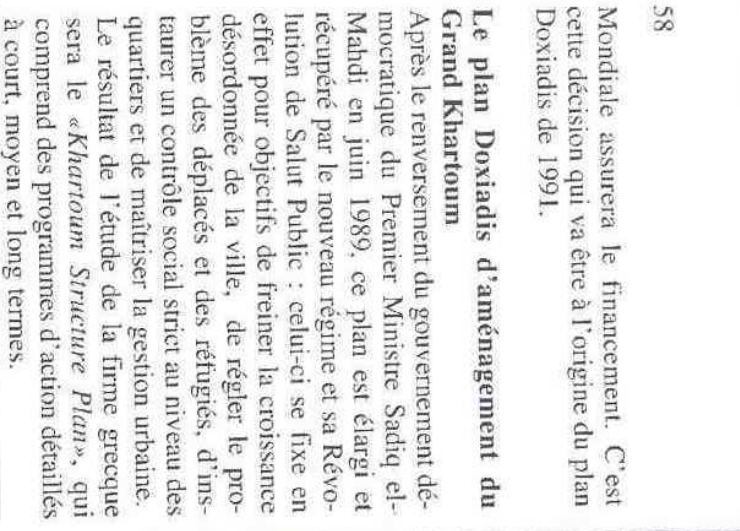

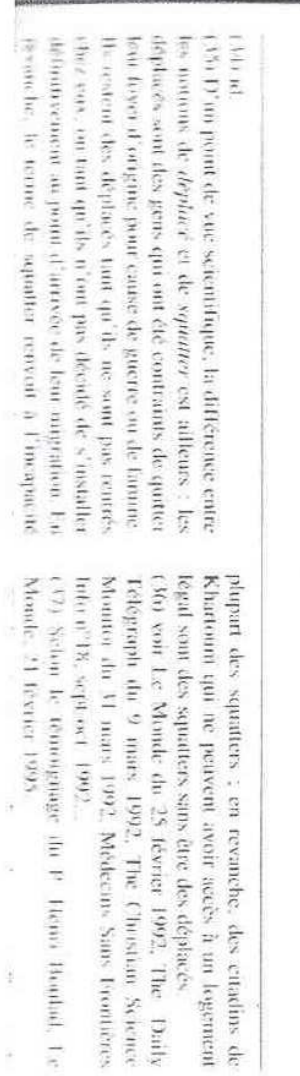

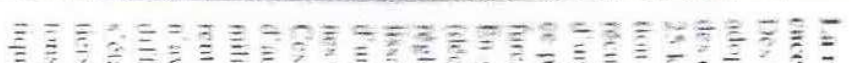

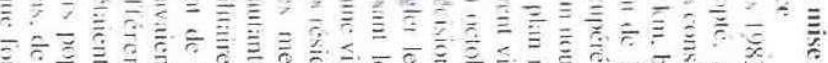

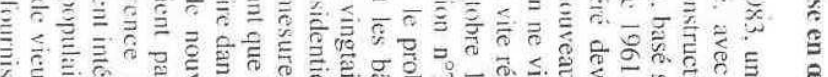

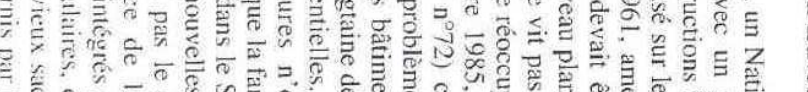

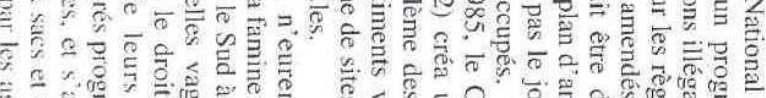

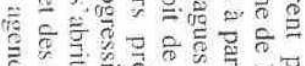

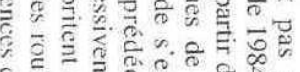

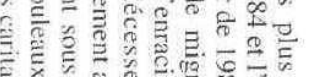
के क्रित्र

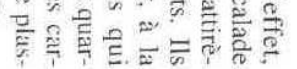

要

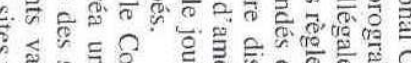

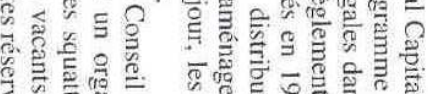

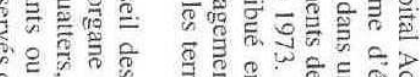
ㄷํㄴ

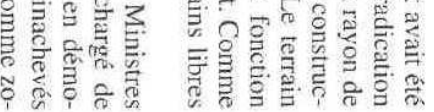

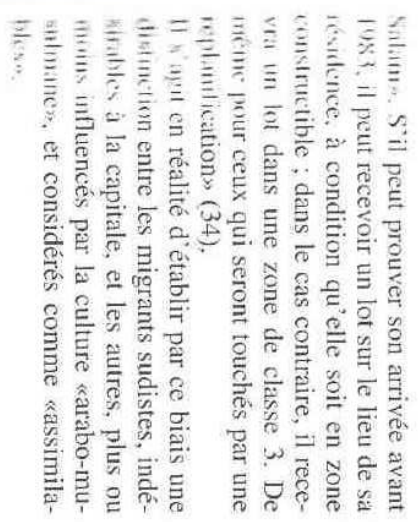

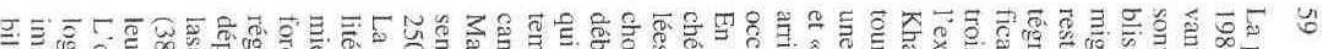

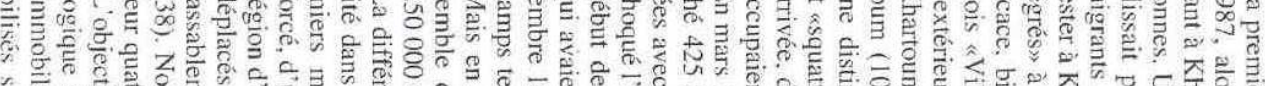

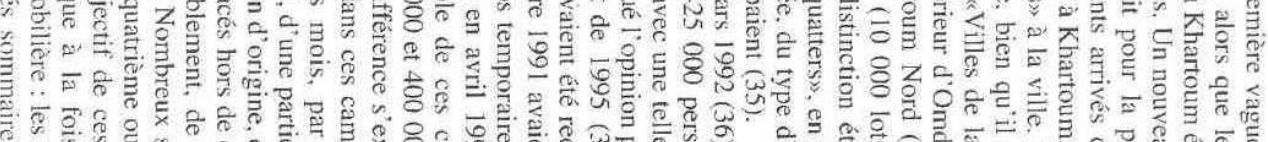

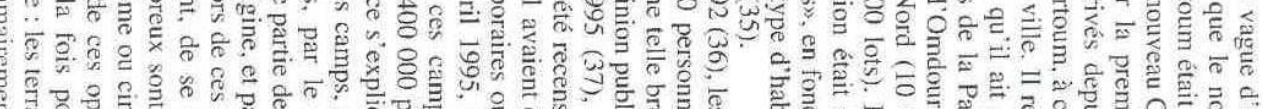

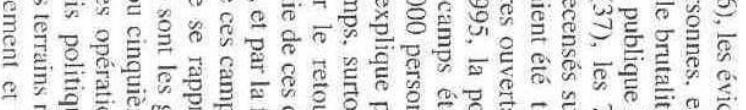

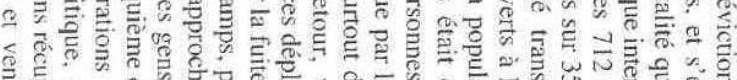

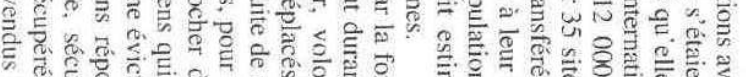

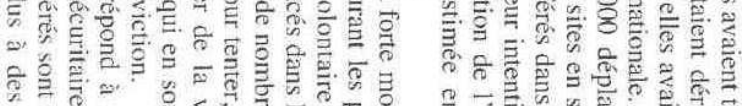
के

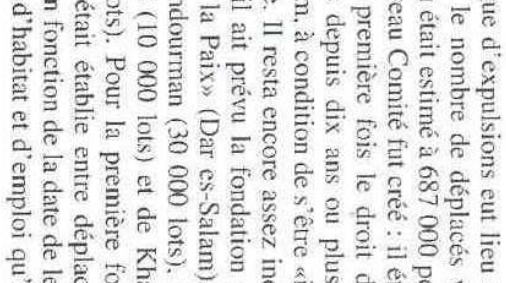




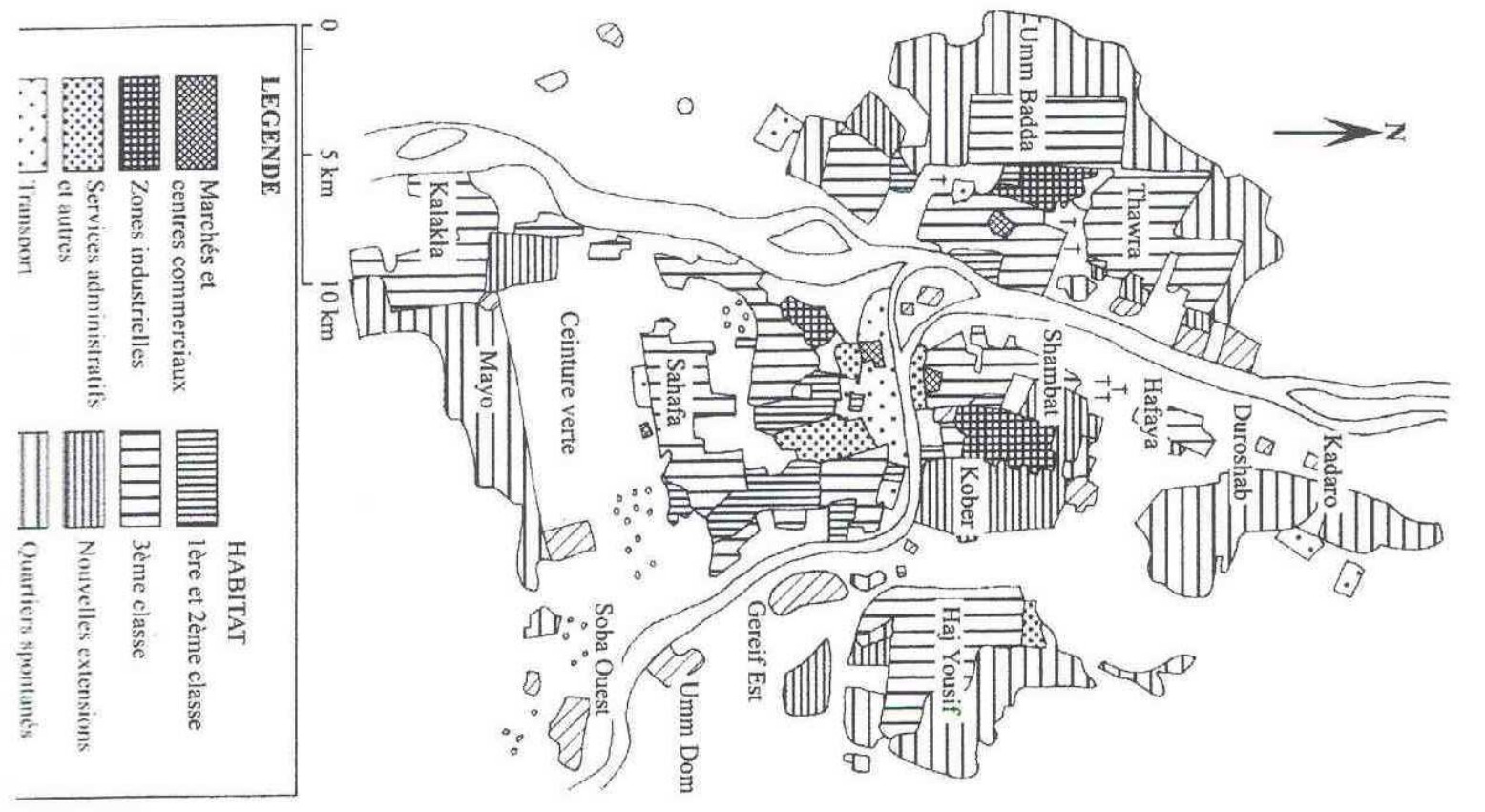

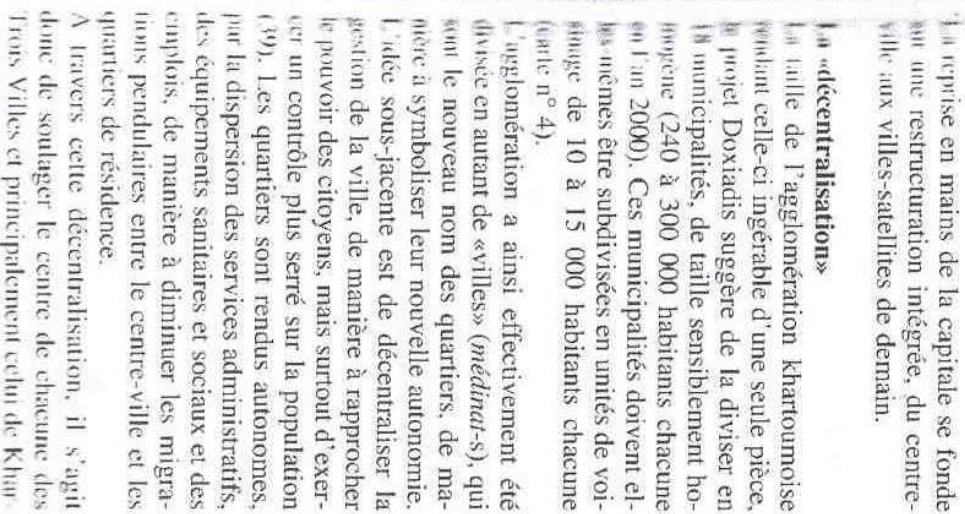

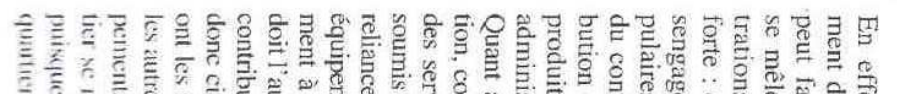

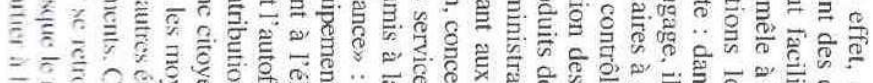

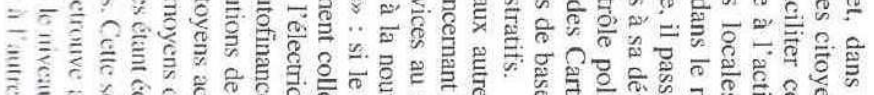

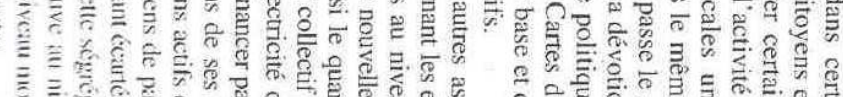

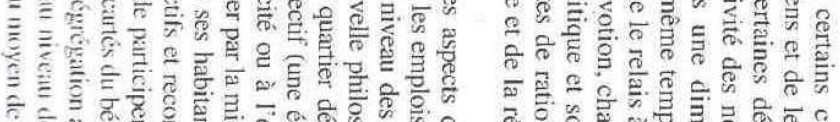

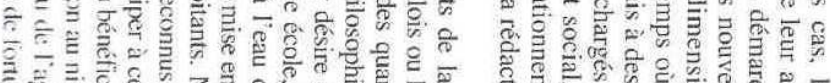

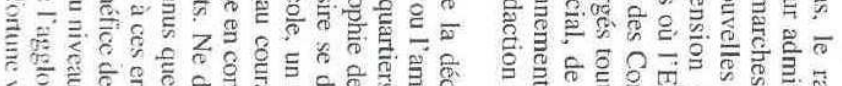

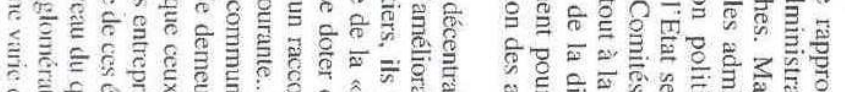

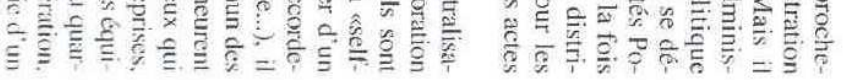




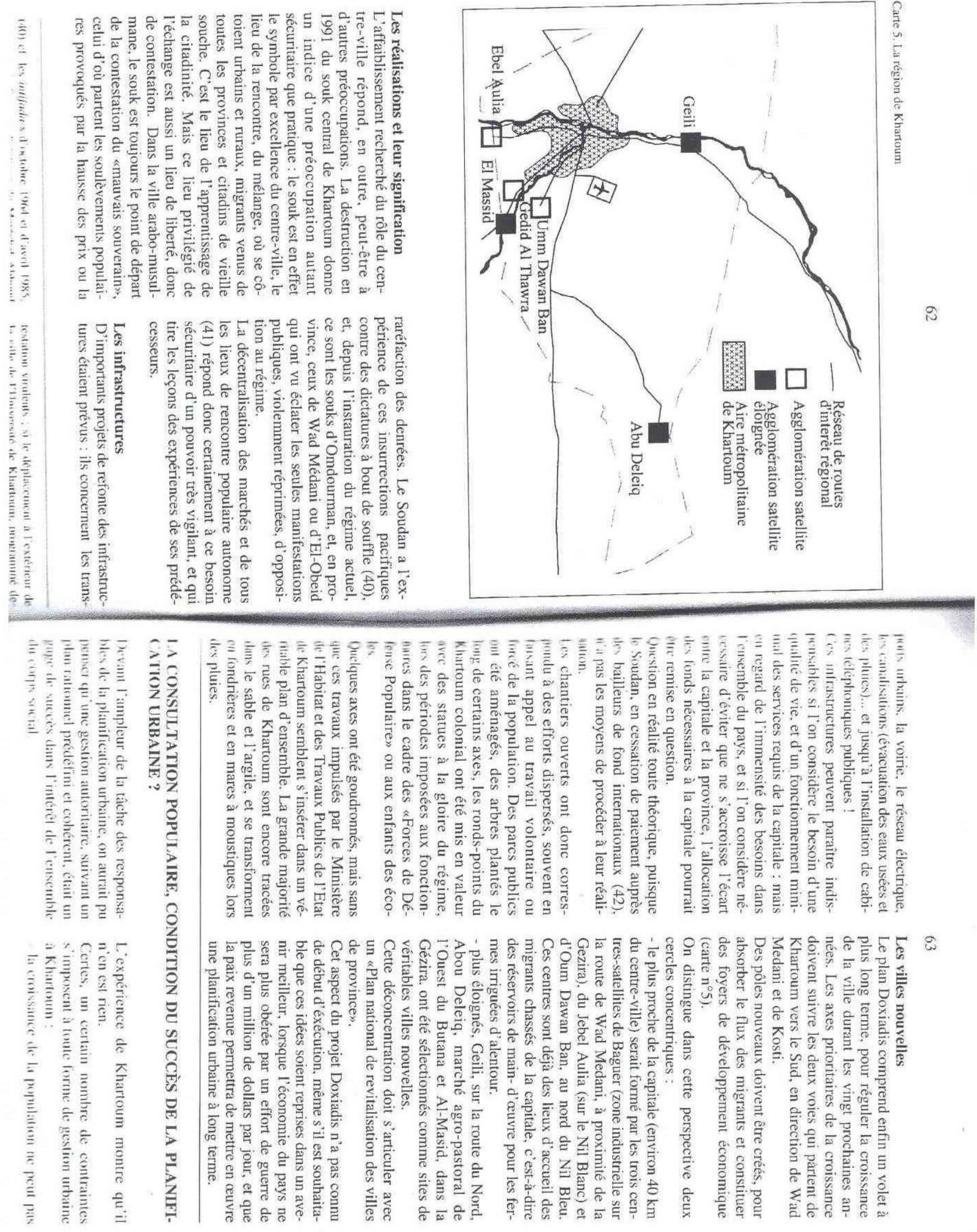

